\title{
Personal Development Planning
}

David Allen, University of the West of England Edited by David Newlands, University of Aberdeen

1 Introduction 2

2 The background to the development of PDP policy 3

2.1 The purpose and outcomes of PDP: three objectives 4

3 PDP and the student: reflection, recording and planning 6

3.1 Reflection 6

$\begin{array}{lll}3.2 & \text { Reflection in learning } & 7\end{array}$

3.3 Recording and planning: the progress file 9

4 PDP and the university: structure, tools and support 10

4.1 Structure: three schemes for recording achievement 10

$\begin{array}{lll}4.2 & \text { Six aims of a PDP programme } & 11\end{array}$

4.3 The progress file and the three objectives 12

$\begin{array}{lll}4.4 & \text { Support for the student } & 15\end{array}$

$\begin{array}{llr}4.5 & \text { The transcript } & 16\end{array}$

5 The challenge ahead 17

$\begin{array}{lll}5.1 & \text { The challenge for the student } & 17\end{array}$

$\begin{array}{lll}5.2 & \text { The challenge for the economics department } & 17\end{array}$

$\begin{array}{llr}5.3 & \text { The challenge for the tutor of economics } & 18\end{array}$

6 Conclusion: creating a framework for reflective learning 19

7 Top Tips $\quad 21$

References $\quad 22$ 


\section{Introduction}

Unlike other chapters, this chapter on Personal Development Planning (PDP) cannot offer a synopsis of widely established practice, or offer a wide range of case studies that help to illustrate the concepts, practices or objectives of PDP in relation to economics education. What we can say is, welcome to the subtle revolution!

'Revolution' because the premise, aspirations and methods embodied in PDP will, if taken to their logical conclusion, herald a change in the way we teach and the way our students learn. Indeed, the wider adoption of PDP will require 'a cultural change and changes to the curriculum, student support and guidance systems, and quality assurance procedures' (QAA guidelines on HE Progress Profiles). The hope is that the reflective processes that characterise PDP will form the basis of lifelong learning and improved career prospects for our students. The shift is towards a process/experience outcome, i.e. it is not what you have learned, but how you have learned that counts. As such, PDP is about reframing and extending existing practice to exploit better the latent potential of our students.

This reframing occurs on two fronts. First, the manner of student support will become more focused and structured. No longer will the tutor be a concerned observer who hopes that students will somehow 'pick up' the skills of self-management and lifelong learning. PDP will require universities actively to assist and facilitate the student in their efforts to acquire these skills. Secondly, the hope is that reflective practice in the context of learning, career and personal development will become embedded in the curriculum of all degree courses.

The subtlety comes from two observations. First, the changes implied by the wide adoption of PDP are not sourced from dictate or policy per se. Rather they are found in the Dearing recommendations, 'which directed higher education institutions (HEI) to develop the means by which students can monitor, build and reflect on their personal development' (Jackson 2001). Secondly, the driving force for the adoption of PDP comes from a collection of groups from within higher education, including University UK, the Standing Conference of Principals (SCoP), Universities Scotland, the Centre for Recording Achievement (CRA), the QAA and the Learning and Teaching Support Network (LTSN) Generic Centre. The changes being sought are therefore the product of networking, discussion and reasoned persuasion. The result is a set of recommendations published by the QAA, which set out the basic requirements that HEIs should refer to when planning to implement a PDP programme.

Full implementation of PDP at undergraduate level is meant to be achieved by 2005/6 and most universities are now making provision. However, because these particular aims of PDP are holistic and require numerous agencies to work together (for example, student records departments, careers advisers and faculty administrators), it does not follow that everybody in a particular university department is fully aware of the changes. This chapter will attempt to digest and interpret these recommendations from the perspective of the economics tutor.

As this is a new project, the QAA recommendations largely cover the desirable minimum features of a PDP programme. For those contributing to the design of a PDP programme, the recommendations are required reading. However, at this stage it is probably best to assume that the majority simply want to know in what ways we as tutors and researchers might be called upon to participate in any PDP scheme. Therefore the purpose and structure of this chapter is twofold. 
First, sections 2-4 attempt to interpret, define and describe what PDP is - specifically in terms of the minimum outcomes recommended by the QAA. In doing this, we can identify the implications for economics tutors of the wider adoption of PDP across the university sector. Sections 2 and 4 draw heavily on two sources: the QAA guidelines on PDP and the various working papers found on the LTSN Generic Centre website. Relying on these two sources is, for the purpose of this chapter, the pragmatic solution to digesting a huge body of literature covering personal development planning. In section 5 some of the wider implications and challenges of the adoption of PDP are briefly explored and considered.

Secondly, section 6 speculates on how reflective practice can be developed within the teaching of economics at level/stage 1 of the degree. At this stage, the suggestions offered can only be viewed as tentative. With time, better ideas will no doubt be developed and shared among economics tutors.

\section{The background to the development of PDP policy}

The aims of PDP are laudable but not benign, since they will require a change in the mindset and practices of many university lecturers. Clearly, a degree of suspicion and uncertainty about the effectiveness of PDP can be expected. For a start, Jackson (2001), on behalf of the LTSN, is candid in declaring that the driving force behind the adoption of PDP is based on a belief rather than any hard facts. He states: 'The moral purpose of what we are doing is to improve student learning ... While we currently lack convincing empirical research evidence the commitment of so many practitioners to supporting PDP is a type of evidence we should not dismiss lightly' (Jackson, 2001, p. 5).

In many respects it seems that the Dearing recommendations have been commandeered by a section of the teaching community to challenge, Trojan horse style, the practices found in many HEIs. Again Jackson (2001) explains that the original National Committee of Inquiry into Higher Education recommendations in 1997 were largely driven by a desire to see better information for employers on the capabilities of graduates, i.e. more detailed paper transcripts of what the students had actually studied. These narrow aims were, however, transformed into the more encompassing PDP project. He is forthright in his justifications:

... the people who cared enough about policy to contribute to its shaping shifted the emphasis from information product to the learning process in order to tap into the fundamental belief systems that motivate teachers. If we motivate teachers because they believe in the process then good information will flow to employers not from pieces of paper but from the lips of our students.

Jackson, 2001, p. 5

The belief that reflection as a process not only assists the individual to plan better but also leads to deeper learning is drawn from the experience of the professions (for example, nursing, 
teaching, social work, law). The intention/hope is that this process can now be widely applied to the teaching of a range of disciplines. Assuredly, the extent of uncertainty surrounding the role of reflection in the professions cannot be understated:

Currently, there is little agreement about what reflection is. Little is known about how it might best be promoted or measured, or, indeed, whether it can be promoted or measured. Nor is there evidence to indicate whether reflective professionals are necessarily more effective than non-reflective professionals. Similarly, there is little evidence to indicate the success, or otherwise, of programmes which seek to promote reflection.

Sumison and Fleet 1996, p. 121

Nevertheless, what we have ended up with is a mixture of both paper and process. The former is a standardised, more detailed transcript of the topics studied and classification awarded, the belief being that over time employers will come to recognise and value the information therein. The latter is clearly more complicated and involved simply because the objective - that of articulate, better-informed and highly motivated students - is a much loftier goal to have chosen. Evidence of the student's journey to this goal will be found in their progress file. Both the transcript and the progress file are the focus of the QAA recommendations.

While this dedicated community of educators might claim to have taken a top-down directive and turned it into a bottom-up initiative, more sceptical tutors/lecturers might feel that they have been bullied (by their own colleagues) into adopting a new approach around which much uncertainty exists. Yet most of us already engage in the support activities that characterise a PDP programme. The main purpose of this initiative is to give structure and direction to what has been a haphazard approach across the higher education sector. In the process, the foundations for deeper learning and greater autonomy in students should be laid. Our job is to find ways in which we as economists can build on these foundations to good effect. Certainly, the proposals as they currently stand give complete freedom to individual lecturers and individual institutions to devise, manage and develop their own particular schemes.

\subsection{The purpose and outcomes of PDP: three objectives}

The QAA guidelines define Personal Development Planning as 'a structured and supported process undertaken by an individual to reflect upon their own learning, performance and/or achievement and to plan for their personal, educational and career development' (QAA, para. 27).

The guidelines state that PDP is:

- a structured process that is integral to higher-level learning;

- concerned with learning in an holistic sense (both academic and non-academic);

- something that an individual does with guidance and support: the latter perhaps decreasing as personal capability is developed so that it becomes self-sustaining;

- a process that involves self-reflection, the creation of personal records, planning and monitoring progress towards the achievement of personal objectives;

- intended to improve the capacity of individuals to communicate their learning to others who are interested in it (for example, academic staff and employers) (QAA, para. 30).

From the QAA guidelines, the stated purpose of PDP is to enable students to:

- become more effective, independent and confident self-directed learners;

- understand how they are learning and relate their learning to a wider context;

- improve their general skills for study and career management; 
- articulate their personal goals and evaluate progress towards their achievement;

- encourage a positive attitude to learning throughout life (QAA, para. 29).

The minimum outcomes from a PDP programme are that students will have:

1. Participated in PDP in a range of learning contexts at each stage or level of their programme;

2. Demonstrated that they can access and use the aids and tools provided by the institution to help them reflect upon their own learning and achievements and to plan for their own personal, educational and career development;

3. With support, created their own learning records containing information on the qualities and skills they can evidence which can be drawn upon when applying for a job or further study (QAA, para. 40).

The QAA is quick to add that these minimum outcomes should not constrain existing practice or local initiatives. In fact, individual HEIs are implicitly encouraged to exceed these minimum outcomes. Nevertheless, this PDP initiative, by including the additional objectives of improved personal development and improved career prospects, means that institutions now have increased responsibilities, ones that extend beyond the improved teaching/learning of economics.

In making a start to accommodate this wider remit, we can compare the QAA objectives to an interpretation offered by Jackson (2001). This interpretation relates 'the qualities, skills, capacities and behaviours that underlie the notion of reflective and planned self-determination' for self-improvement. To this end, students should be able to:

- demonstrate a responsible attitude to their personal, educational and career development;

- identify what needs to be done to improve something;

- recognise opportunities for new learning;

- create a strategy for self-improvement or change;

- manage time/competing demands to achieve desired objectives;

- monitor and review progress towards the achievement of goals and targets;

- change the strategy if it is not working;

- justify and account for their personal strategies

Jackson's interpretation is useful in that the verbs he uses are more explicit and describe well the activities involved in PDP. Clearly a framework wherein these activities occur and are evidenced is required. In PDP, the student's progress file provides this framework - it is the 'means by which students can monitor, build and reflect upon their personal development' (Jackson, 2001).

The QAA document then goes on to identify the likely benefits of PDP from the perspective of the student, the HE institution and the employer. We might presume that the government believes that a learning society is a productive and adaptable society - thus if economic growth is intimately linked with human capital then PDP will aid its development (Bolhuis, 2002). For academic staff the benefits of PDP are:

- helping students to be more independent/autonomous learners;

- improving the quality of experience for tutors and tutees when it is linked to personal tutoring systems

- making more effective use of off-campus opportunities for learning, such as work placements or study abroad; 
- creating a mechanism through which career-related skills and capabilities can be recorded;

- improving understanding of the development of individual students and tutors' ability to provide more meaningful employment references on their behalf (QAA, para. 35).

From all of the above, we can discern three basic activities that students are expected to undertake: reflection, recording and planning. Universities are then responsible for creating a structured process at all levels of a degree course, providing the necessary tools and support for these student-led activities.

The purpose of all of this is to help students to recognise and then 'shape' their perceptions of their abilities and progress as individuals. What should result from PDP is an individual with 'enhanced self-awareness of strengths and weaknesses and directions for change' (QAA, para. 32). Taking each of these activities in turn, we can offer some definitions, descriptions or clarifications from the perspective of the student and the university.

\section{PDP and the student: reflection, recording and planning}

\subsection{Reflection}

Moon (2002) provides us with a summary of the four main 'classical' theoretical perspectives on reflection. For Dewey (1933), reflection is thinking about 'me' as the individual and 'my functioning' as an individual. It is this focus on reflection - that of strengths and weaknesses that perhaps typifies the holistic aspirations behind PDP. Kolb's (1984) cycle of experiential learning is perhaps the one concept with which many of us will be familiar. The usual interpretation is 'learning by doing' - but some challenge this narrow interpretation. Schon's $(1983,1987)$ concern was to reconcile or explain the differences between theory and practice in the professions. Professionals build up expertise through reflection, not necessarily by applying the training provided in formal settings. Schon suggests that two types of reflection occur: 'reflection-in-action', such as remembering a similar problem and recalling its solution, and 'reflection-on-action', which occurs after the event. According to Habermas (1971), reflection is about how we process knowledge and construct new knowledge or build theories. He identifies three types of knowledge: instrumental knowledge is our existing inventory of understanding; interpretational knowledge is the understanding that we use to make sense of our surroundings; and critical or evaluative knowledge is used to process the first two, which then leads to new understanding.

All the above ideas are plausible and each describes different types of reflection depending on the purpose of reflection. Moon argues as much by stressing the context of reflection, be it learning (Klob), professional conduct (Schon) or theory building (Habermas). Dewey's perception, however, is more holistic. Moon (2002, p. 2) offers her own 'common sense' definition of reflection: 
Reflection is a form of mental processing - like a form of thinking - that we use to fulfil a purpose or to achieve some anticipated outcome. It is applied to relatively complicated or unstructured ideas for which there is not an obvious solution and is largely based on the further processing of knowledge and understanding and possibly emotions that we already possess.

This commonsense view suggests that reflection is essentially a problem-solving or decisionmaking process. The purpose is to enable the individual to understand where they have come from, where they are and where they are going. In relation to Jackson's objectives for a PDP programme, reflection identifies the problem, creates the strategy to solve it and monitors progress to this goal. A reflective habit is then integral to planning for improved career and personal development.

\subsection{Reflection in learning}

If Habermas's explanation is valid, it is likely that the role of reflection in the learning of any particular theory will take a similar route. The degree to which a student engages in reflection might then distinguish a deep approach to learning from a surface approach. This can be illustrated by the Economics benchmark statement, which identifies two levels of performance: the threshold level and the modal level. Taking two examples from these classifications, we can get an idea of the difference between the two levels:

\section{Threshold}

- Demonstrate knowledge of economic theory and modelling approaches.

\section{Modal}

- Demonstrate understanding of economic theory and modelling approaches, and their competent use

Clarifying the meaning of knowledge and understanding, the benchmark statement offers the following guidance: 'Knowledge is the ability to reproduce theory and evidence as taught, understanding is a term applied to constructive and critical use and analysis of that material.' In this context, knowledge is the act of simple recall and memorising. Conversely, understanding can be taken to mean some amalgam of higher-order skills, where the student interprets new knowledge in relation to their existing knowledge to develop a new level of understanding.

The student's achievement of either level would clearly reflect their application to learning. Relevant to this, Moon (2002, p. 6) contrasts a deep approach to that of a surface approach:

A deep approach is where the intention of the learner is to understand the meaning of the material. She is willing to integrate it into her existing body of previous ideas, and understandings, reconsidering and altering her understandings if necessary. The new ideas are 'filed' carefully and integrated. In contrast, a surface approach to learning is where a learner is concerned to memorise the material for what it is, not trying to understand it in relation to previous ideas. It is as if new ideas need to be retained for the moment, but not 'filed' for any lasting purpose.

Moon also provides us with five stages of learning which move from surface learning to deep learning, arguing that reflection occurs in the latter stages, facilitating deeper learning: 
Noticing

Making sense

Making meaning

Working with meaning

Transformative learning
Being observant, you cannot learn something if you do not notice it. Getting to know the material as coherent, fitting the facts together like a jigsaw, but not relating the material to other ideas.

The start of relating the new material to other ideas, putting it into context.

'Going beyond the given'. Linking of the new material to existing ideas, as a result of which the learner's overall understanding may start to change.

Ideas and understanding are now restructured, and the learner is able to evaluate the processes that lead to this new learning.

(Adapted and interpreted from Moon, 2002, p. 6)

Moon (2002) suggests that the first two stages represent surface learning and the last three stages represent deeper learning and are characterised by the activity of reflection. The learner is using reflection to make sense of the material - putting it into context and identifying where it comes from and where it is going. This process of reflective learning mirrors the taxonomy of Bloom (1956), which we as tutors often refer to when assessing students' understanding. These similarities are summarised in Table 1.

\begin{tabular}{|lll|}
\hline \multicolumn{2}{|l|}{ Table $\mathbf{1}$ The symmetry between reflective learning and the assessment of knowledge } \\
\hline $\begin{array}{l}\text { Stages of } \\
\text { reflective learning }\end{array}$ & $\begin{array}{l}\text { Bloom's (1956) } \\
\text { taxonomy }\end{array}$ & The student's task \\
\hline Noticing & Knowledge & Able to recall taught material \\
\hline $\begin{array}{l}\text { Making sense and } \\
\text { making meaning }\end{array}$ & Comprehension & $\begin{array}{l}\text { Able to demonstrate the meaning of } \\
\text { taught material }\end{array}$ \\
\hline & Application & $\begin{array}{l}\text { Able to use taught material in new and } \\
\text { concrete situations }\end{array}$ \\
\hline Working with meaning & Analysis & $\begin{array}{l}\text { Able to break down taught material into its } \\
\text { component parts }\end{array}$ \\
\hline Transformative learning & Synthesis & Able to join taught material to form a whole \\
\hline & Evaluation & $\begin{array}{l}\text { Able to judge and value material, for its own } \\
\text { worth and its greater relevance }\end{array}$ \\
& &
\end{tabular}

These stages of learning describe the role of reflection in learning. In addition, the process has inherent benefits for both the tutor and the student. Moon (2002, p. 8) suggests the following benefits:

- Reflection slows down activity; the learner has time to process the material, linking it to previous ideas.

- Reflection gives learners a sense of 'ownership' of taught material, making it more personally meaningful.

- It encourages metacognition, where metacognition is the awareness of one's own cognitive processes - in this case, learning. Citing evidence from Main (1985), it seems that study skills programmes that support the learner's awareness of learning processes are more effective than those that focus on technique.

- Encouraging students to reflect challenges their learning - we are seeking a greater commitment to it. 
This last benefit is probably less attractive to the student than it is to the tutor. For this reason the motivation to undertake reflection is less clear-cut in learning than it is in personal and career development. For economists, the problem of motivation is readily apparent - the likely 'payoff' to such a commitment or investment in time is uncertain.

To explain, a student of economics may decide to go on and train to be an actuary. Information as to what skills and talents are required for such a job is both accessible and transparent; as such the route to this goal can be planned. Similarly, the rewards for choosing such a course of action are very apparent. However, what distinguishes an Upper Second from a First (i.e. the payoff) and the route to either goal is often less apparent to the student. It follows that to motivate the student to undertake deeper learning, the goal and the way to achieve it have to be more explicit. To reap the benefit of reflective learning, tutors may have to revisit their programme specifications and performance criteria.

All the above modes of reflection have one thing in common: reflection can occur only by first reviewing an 'inventory' of existing evidence, information or knowledge. The objectives of PDP explicitly address this by insisting that institutions provide the tools (i.e. the progress file) where this evidence or information can be stored, organised and 'mulled over'.

\subsection{Recording and planning: the progress file}

The use of PDP in professional training and skills training is a well-established practice. Many will be familiar with the process by other names - for example, personal profiling, personal and academic records, personal (academic) development plans, learning portfolios, learning logs and diaries. In PDP, the term used is progress file, which, in the context of the objectives of PDP, is best thought of as a 'map' or more crudely as a list of things to do. The purpose is to enable students to 'see' where they have come from, where they are and where they are going.

The progress file is therefore the main pillar of any PDP programme. Individual institutions will have to assemble these maps, and provide them to the students (see section 4.5). Most pilot schemes start out as paper-based systems but the trend is towards web based programmes that a student can access at any time.

It is perhaps the idea of record keeping that appears the least attractive aspect of PDP. Jackson (2001) observes that, given the many mistakes from the 'systemisation of records of achievement' in schools during the 1990s, it is 'surprising that the government's response to Dearing firmly located HE PDP back in the piece of paper mindset' (Jackson, 2001, p. 6). Mindful of Jackson's observation, the QAA document notes that many students will be familiar with this aspect of PDP - therefore one might expect a collective groan from the student body when introducing them to PDP.

However, for all concerned the records will serve two purposes. First, and in terms of the minimum outcomes (number 3 in particular), they are both the 'inventory' and 'evidence' of skills, experiences and achievements (both academic and non-academic). In the final analysis, such records should help the student to marshal their resources and assess their achievements in relation to any career target they may have set themselves. In one respect, these records become the scripts that the student rehearses when applying for a job or a place on a higher-level degree.

Secondly, and perhaps more importantly, the records will aid the discussion between the student and their personal tutor. Here, the literature surrounding PDP could make this justification more explicit, particularly in that the records enable both people to communicate on common ground - they delineate the boundaries of discussion, advice and negotiation.

For subject tutors, discussions with students who have identified their strengths and weakness by reference to their inventory should become more fruitful. Discussions on, say, elasticity might 
then extend beyond 'I don't understand it.' Instead of having to probe the student to try and find out what it is that they find difficult about elasticity, we could expect a more focused dialogue. There is, in all this, going to be subtle shift in the tutor/student relationship, in that the self-directed student will realise they have a responsibility to meet the tutor halfway by at least attempting to self-diagnose part of the problem - the records may assist this by enabling students to evaluate their progress in particular topics.

\section{PDP and the university: structure, tools and support}

\subsection{Structure: three schemes for recording achievement}

The QAA provide two frameworks (found in Appendix 2 of the QAA guidelines) that should help those devising their programmes to make explicit the ways in which they are promoting PDP. In essence, there are three types of programme for recording a student's achievements.

\section{Negotiated Learning Outcomes Profiles}

These are integral to the learning framework (i.e. a formal course of training). Students set their own learning goals (in relation to the course/award objectives), which are then formalised in a learning agreement. How these goals are achieved, judged and evidenced is decided by the student with the mentor or tutor providing guidance.

These programmes are often associated with competency/skills-based knowledge and practice, and might be used in work placements and sandwich courses. Otherwise, they are a useful framework when a particular course entails a high degree of student autonomy - for example, when students are studying abroad as part of their degree. They not only help to guide the student to make their time away more productive, but also provide invaluable information on the student's progress.

\section{Personal Development Profiles}

These would be programmes that are complementary to the teaching and learning framework. Students are encouraged to set their own personal, learning and career goals, and to monitor their own progress against these objectives. This approach is usually supported or incorporated into a personal tutoring system, the tutor acting as a facilitator/mentor.

These types of scheme in essence mirror what might already occur in many economics departments, but as already stated the purpose is to give structure and direction to the efforts already being made. Within these schemes we might find 'free-standing' or 'bolt-on' courses or modules on career development, CV preparation and the like. A good, accessible example of such a programme is the PADSHE (Personal and Academic Development for Students in Higher Education) Project, based at Nottingham University. 


\section{Programme Learning Outcomes Profiles}

These are integral to the learning framework (i.e. the programmes and modules included in any named award) and the learning outcomes are made explicit. As such, they are the defined goals against which the student's progress is evaluated.

This last scheme is similar to the second scheme, but here the focus is closely associated with developing the student as a professional (for example, nurse or lawyer). The learning outcomes and targets are drawn from the benchmark statements set by professional bodies or national organisations. Such schemes might be considered rigorous in the sense that meetings between students and tutors are more formal events with clear agendas regarding targets and may also entail a degree of formal assessment. It is likely that these schemes would cover the duration of the award. However, this does not mean that similar schemes cannot be applied to nonprofessional courses (for example, a third-year dissertation/project).

\subsection{Six aims of a PDP programme}

Within these three schemes, there are six basic aims that can be targeted; combinations of these aims should then ensure that the three main objectives of PDP are addressed.

These aims include support of: (1) off-campus learning (as above), (2) preparation for employment/professional practice (as above, but not exclusive to the professions) and (3) extracurricular learning. Extracurricular activities cover a whole range of activities, including part-time work, work as an NUS officer, charity/community work and so on. The latter is an interesting development in that students do not often realise just how experienced and capable they are, or that such extracurricular activities provide evidence of the skills and achievements recorded in their progress files. To this end, the NUS is actively developing a PDP programme in conjunction with the University of Hull, the hope being that this pilot scheme will eventually lead to work experience being subject to accreditation by the university. Likewise, the NUS 'Insight Plus' programme seeks to build on such pilot schemes and establish a framework for the accreditation of work experience across the university sector as a whole.

In terms of learning, there are two principal aims (or approaches). The first of these is (4) support for the learner. Again, this objective is often linked to the personal tutoring system. Students are encouraged to develop as individuals through self-profiling and identifying learning opportunities within and outside the curriculum.

The second learning aim is (5) support for learning. Here, the objective is to improve the capacity of the individual to manage his/her own learning by (a) making the learning outcomes of modules/course more explicit and (b) creating the opportunity for students to reflect on and assess their learning. (a) requires definition of the 'targets' that students will aim to achieve. In (b), 'creating the opportunity' can be interpreted as setting these targets down on paper (or online). These then become the basis of the progress files - the 'maps'. The intention is that the student should enter into a dialogue about these reflections and assessments with their tutor/mentor.

The difference between the two objectives is subtle but, broadly, support for learning is more closely associated with Programme Learning Outcome Profiles and support for the learner is more associated with Personal Development Profiles.

One further aim remains, one which is perhaps more contentious. (6) The stated aim is that all PDP programmes should be 'a means to demonstrate that broader expectations of a high quality educational experience are met'. Clarifying this particular aim, the QAA suggest that these expectations would be those 'contained in the Subject Quality Assessment Framework/HEQC Guidelines for student support for the effective integration of transferable skills' (QAA, appendix $2 a)$. These guidelines trace out the attributes associated with "graduateness". It is unlikely that 
this aim would be presented as a specific section in any progress file; rather the identification of, and reflection on, these transferable skills should be evidenced in the aims already discussed.

In this respect, the QAA guidelines recognise that many academics may view progress files 'as merely ways in which QAA can check on the delivery of programme specification' (QAA, appendix 3). At this stage, those supporting the PDP initiative can only hope that most academics will see that progress files are a means to an end and not an end in themselves.

The permutations for any PDP programme are clearly numerous. We have three methods and six aims, which can then be applied over the three levels or stages of a degree programme. How each institution will configure its programme is up to the institution, but it is probably determined to some degree by the nature of the award. Similarly, the encompassing nature of the objectives means that various agencies will be contributing to the institution's project. Nevertheless, from the minimum outcomes, any chosen structure has to enable the student to address the objectives of improved learning, improved career prospects and personal development at each level of the degree.

\subsection{The progress file and the three objectives}

As already indicated, the progress files define the system. They are the main tool of the system. If these maps/records are to be of any value, each objective of PDP then needs to be addressed in a thorough manner. Taking the three objectives in turn, we can get some idea of the work ahead.

\section{Improved learning}

In terms of improved learning, the intention is to engage students in 'deep' learning through greater reflection on the material encountered over the course of their degree. It is hoped that PDP will provide the framework for students to plan to improve their academic performance. Therefore module leaders will have to ensure that the learning outcomes of their courses are explicit, not only in terms of intended outcomes or the processes that enabled these outcomes to be achieved, but also as regards the performance criteria against which the achievements are measured. More to the point, there might be a need to re-engineer many of our existing learning outcomes and performance criteria in a language that is accessible to students - or at least provide translations! After all, if students are to set targets (be they learning ones or otherwise), they have to understand them. It follows that all module leaders will be involved in PDP at the planning stage at least, if only in supplying these learning outcomes to the people assembling the progress files. How we get students to reflect on these targets is up to individual institutions. Nevertheless, the outcome of these reflections will be the basis of discussions between the tutor and student under one of the three schemes already discussed.

Devising a PDP programme that explicitly tackles academic development is difficult compared to PDP programmes for personal development and career development. The inference, given the examples of the transcripts found in the QAA guidelines, is that a third-year dissertation/project is the most likely vehicle to achieve this target. If so, the way these projects are run may have to change to incorporate the 'features' of a PDP programme, namely: a process that involves selfreflection, the creation of personal records, planning and monitoring progress towards the achievement of personal objectives.

Heylings and Tariq (2001) provide a good example of such a scheme for biology students; as such, it could be applied to economics projects that are quantitative in nature. The main features of their scheme are:

- the submission by students of three interim progress reports and the provision of written and oral feedback by staff; 
- a requirement that students maintain a project log book;

- a skills self-evaluation exercise to encourage students to reflect on their learning.

The 'time-line of formal action points' (Heylings and Tariq, 2001, p. 156) during the project gives a clear idea of what is to be achieved. A shortened version of this timeline is found in Table 2, although this should not be interpreted as anything but an example. Similarly, the selfassessment skills mix 'inventory' or pro forma is reproduced, as Table 3, to give a flavour of what is expected of the student in terms of reflecting on their own performance.

Table 2 Monitoring student progress during an honours research project

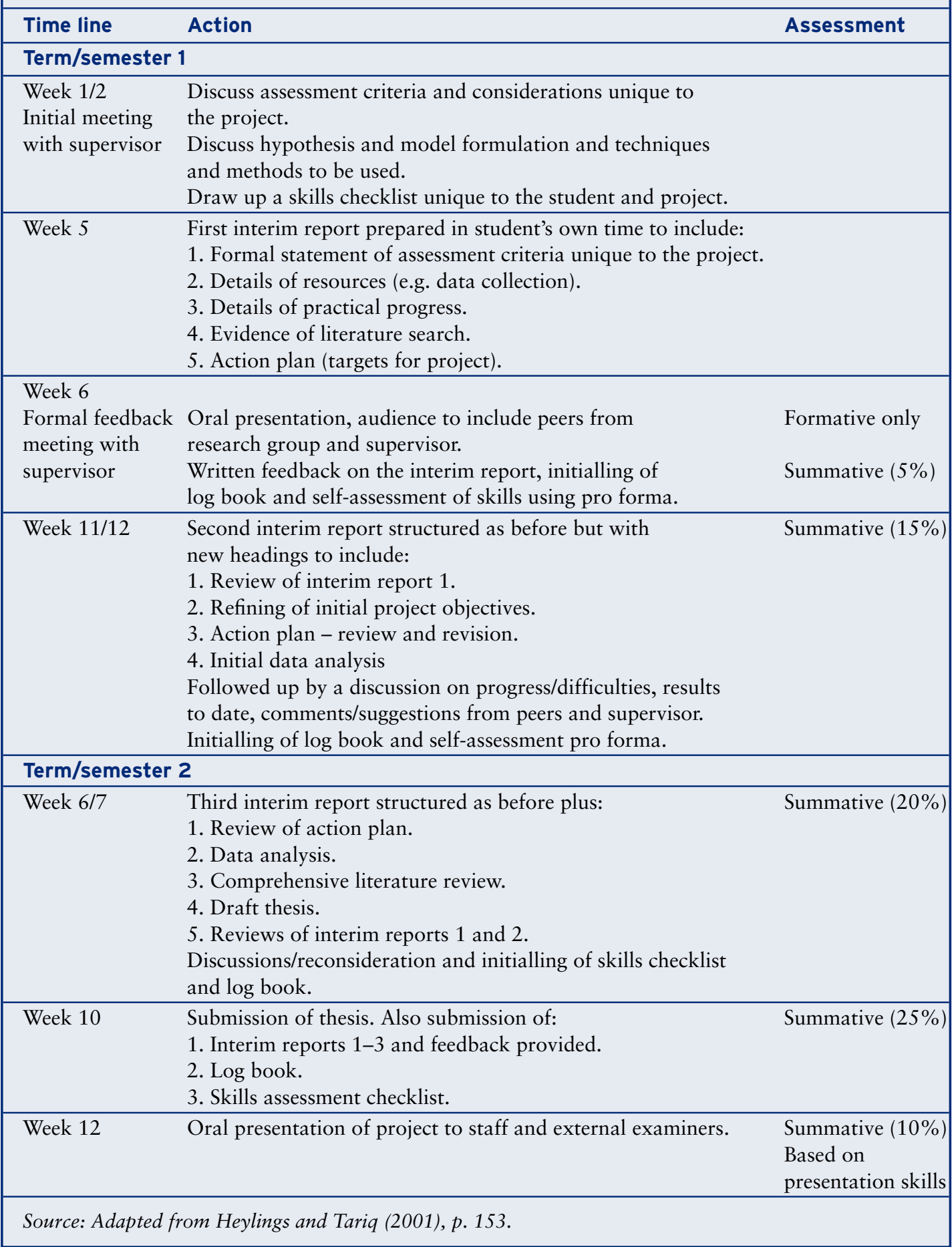




\begin{tabular}{|c|c|c|c|c|c|}
\hline \multirow[t]{2}{*}{ Transferable skills } & \multicolumn{5}{|c|}{ Score } \\
\hline & 1 & 2 & 3 & 4 & 5 \\
\hline \multicolumn{6}{|l|}{ Commitment } \\
\hline \multicolumn{6}{|l|}{ Punctuality/attendance } \\
\hline \multicolumn{6}{|l|}{ Initiative } \\
\hline \multicolumn{6}{|l|}{ Attitude } \\
\hline \multicolumn{6}{|l|}{ Independence } \\
\hline \multicolumn{6}{|l|}{ Time management } \\
\hline \multicolumn{6}{|l|}{ Negotiating skills } \\
\hline \multicolumn{6}{|l|}{ Interpersonal skills } \\
\hline \multicolumn{6}{|l|}{ Accuracy/numeracy } \\
\hline \multicolumn{6}{|l|}{ Data analysis/statistics } \\
\hline \multicolumn{6}{|l|}{ Computer skills } \\
\hline \multicolumn{6}{|l|}{ Oral presentation } \\
\hline \multicolumn{6}{|l|}{ Written presentation } \\
\hline \multicolumn{6}{|l|}{ Other } \\
\hline \multicolumn{6}{|c|}{$\begin{array}{l}\text { Scale definition: } 1=\text { very poor; } 2=\text { poor; } 3=\text { satisfactory } 4=\text { good; } 5=\text { excellent; } \\
\text { N/A = not applicable. }\end{array}$} \\
\hline \multicolumn{6}{|c|}{$\begin{array}{l}\text { The grades on this sheet are for self-evaluation purposes only and will not be used in the formal } \\
\text { assessment of the course work. }\end{array}$} \\
\hline Signed: & (supervisor) & & Date: & & \\
\hline Signed: & (student) & & Date: & & \\
\hline
\end{tabular}

\section{Improved career development}

The intention is to ensure that skills which will enhance the student's employability are increasingly embedded into the curriculum. Specific professional courses, such as engineering, are probably easier to configure, in that the academic targets and skills targets have already been identified and form the bulk of the existing curriculum. However, for courses such as economics that are not specifically linked to a profession, career development is likely to focus on the generic vocational/key skills that improve the student's employability.

In making a start, many universities have adopted the HEQCA criteria. One example is Bradford University's 'Excellent Plus Strategy'. Here, module leaders have been called upon to review or audit their course's key skills coverage and explicitly identify the skills that their particular courses either use or develop.

More generally, some modules may have to be adapted to ensure greater coverage of key skills in the award's curriculum. Similarly, if any of these skills are to be assessed, the steps that lead to achievement will have to be identified for the purpose of target setting. Finally, if students are to 'speak' of their achievements, we should provide them with a language they can use in a nonacademic setting.

Besides adopting the HEQCA criteria for skills, many universities will be drafting in their careers departments to advise or identify the skills that various employers require. These targets, and how and where they can be achieved, are collected together in a progress file that students can consult and use to evaluate their progress. It is also likely that these departments will devise 
and supply courses on career development. For economics, there is a pressing need for better information on which organisations employ economists.

Similarly, it might be that by lodging more information on the study of economics at a higher level, more students might 'target' a PhD in Economics as a career aspiration. To this end it makes sense to identify the skills required to undertake a PhD somewhere in the student's progress file.

\section{Improved personal development}

For students, and in the context of PDP, personal development is the act of initially 'taking stock' of your present skills base, seeking evidence across a whole range of activities (academic or otherwise). Here again the NUS is taking a lead in developing a personal development planner called the 'Skills Manager'. This is to be an online tool designed to give students 'the opportunity to record, reflect and plan their experiences and accomplishments, using them to increase their employability and identify their transferable skill'. The skills listed in the audit include: communication, creativity, problem solving, teamwork, leadership, money management, managing yourself and information technology.

It seems desirable that students themselves should define the personal skills they believe are relevant to them. To this end universities who plan to use the NUS planner might reciprocate and try harder to find ways of accrediting work experience.

\subsection{Support for the student}

Explicit to all three structures is the role of the university in providing support to the student. In effect, universities are being given a more active role in the student's development; rather than teach and test, there is scope to act (and be recognised) as a coach or mentor.

Who will do the coaching depends on the scheme chosen, but given the emphasis on improved learning it is generally accepted that practising academics should participate, be they personal tutors assigned a group of students for the life of the degree or lecturers on specific modules (for example, dissertation supervisors).

From the QAA guidelines, the key lessons learned from universities that have already implemented PDP is that it is most effective when it is:

- a mainstream academic activity;

- linked to the learning objectives/outcomes of programmes;

- undertaken regularly;

- supported and valued by staff (QAA, para. 47).

In particular, observations on the features of policy and practice 'that are known to be successful' include:

- provisions that ensure students have appropriate and regular access to a named individual who will support (and challenge) the student through the PDP process (QAA, para. 48).

It is possible that students will have numerous 'mentors' during their time at university, but presumably the minimum number of meetings would be twice a year, once at the beginning and once at the end of the academic year. An agenda, which has been previously agreed with the student, would make for a more productive encounter. It is interesting to note that Dr Angela Smallwood, the Director of PADSHE, finds anecdotal evidence that since academic support is so integrated and visible within PADSHE, 'fewer students claim time from staff on an ad-hoc basis'. 
For professional programmes such as nursing, where reflective practice is an established procedure, the role of the practitioner/academic is obvious. For economics, the need for the academic to take this role may not be so apparent. Put another way, employing student advisers to support students in their personal and career development seems attractive. However, we could not expect a student adviser who has no background in economics to be able to assist a student who is having difficulties with, say, the concept of normal profit. Likewise, in modular schemes the academic tutor is better placed to give advice on what optional modules may be appropriate - given the student's abilities and aspirations.

\subsection{The transcript}

Details of the transcript can be found at the QAA website. All institutions will be responsible for collecting the information found in the transcript. For this reason, most universities seem to be handing the task over to a centralised records office so that extra copies of transcripts can be supplied as graduates filter through to the job market.

The major innovation is the inclusion of all modules studied over the duration of any particular award, irrespective of whether the module's mark is used in determining the final degree classification. Furthermore, the transcript will show how many attempts were made at any particular module. The inclusion of the number of attempts made might have an impact on those students content to take a more relaxed view about their academic achievements.

In addition to the above, it is intended that the transcripts will include or identify where any formal opportunities for Personal Development Planning have occurred. The examples shown in the QAA guidelines indicate that specific modules, such as a dissertation/project, could be included or that a series of workshops on, say, An introduction to Personal Development Planning or Career development skills could be identified. This suggests that for topics like economics most PDP schemes focusing on personal development and career development will probably be treated as complementary to the main learning and teaching framework.

Furthermore, formal opportunities can be interpreted as those that have some element of assessment. So in the case of a Personal skills course or a Career planning course, the assessment might be simply a pass/fail mark that is not included in the final degree classification. Obviously, if the project/dissertation is used as a formal PDP opportunity, the subsequent mark will reflect the student's application in the area of reflective practice and 'academic development'. 


\section{The challenge ahead}

\subsection{The challenge for the student}

The assumption underpinning PDP is that students will seek improvement - that they are maximisers, and will therefore devise a plan of action as a result of reflection. The aspiration behind PDP is that students will 'learn to learn' and become more autonomous in their learning.

However, little is known about students' attitudes or ability to conduct self-directed learning. Kreber (1998) presents evidence that the psychological make-up of students might to some extent determine their willingness to engage in self-directed learning. She contends that less willing students are 'initially uncomfortable with the unwanted freedom, flexibility and responsibility' that a self-directed approach to learning implies (Kreber, 1998, p. 84).

Similarly, Fazey and Fazey (2001) show that while first-year students have a positive perception of their potential for autonomous learning behaviour, they are uncertain of their abilities in this area. The latter implies that 'learning to learn' could be treated as a skill - one that tutors simply need to 'teach'. Yet there are diverse views as to what constitutes 'learning to learn' (Waeytens et al., 2002).

If, as Rowson (2000, p. 225) suggests, 'learning to learn' is likely to be a 'package of skills, involving study skills, critical analysis, time management, planning, goal setting and so on', then student expectations of university will also have to change. Compared to the conventional, more passive approach of 'teach and test', reflective learning will require a different, if not greater, commitment. Indeed, it is very likely that students prefer to 'connive' with the product/outcome approach 'as a due paid in order to receive a marketable qualification' (Rowson, 2000, p. 232). Swann (1998) makes a similar argument that students and tutors collude in the 'idea that alternatives to the current approaches to do not exist' (cited in Rowson, 2000, p. 235).

Finally, it seems that the proponents of PDPs might find their progress is checked, not by the conservatism of their colleagues, but by the conservatism of their students. Vermetten et al. (2002) report on a project to introduce 'student-orientated education' in Tilburg University (Netherlands), but despite the participation of all staff, the results were not encouraging in that student surveys showed little change in learning behaviour. The important 'mediating factor seems to be the habitual learning approach' (Vermetten et al., 2002, p. 256). Elaborating, 'In the constructivist view, individuals view the world in a personal way, and construct their own meaning. The present study suggests that a person's habitual way of learning and learning conceptions influence the appreciation and use of elements of the learning environment, and therefore diminish the intended impact of instructional measures' (p. 282).

Many of these problems might be easily tackled by more explicit academic targets. Otherwise, it is likely that the student's perception of what is entailed when learning at university will have to be reshaped.

\subsection{The challenge for the economics department}

Despite the above, institutions are urged to encourage students in 'reflective practice'. The PDP initiative expects institutions to put in place structures that facilitate and support the activity. In this sense the pastoral or 'functional' objectives of PDP are worthy. Furthermore, encouraging 
reflective practice is justified if personal development is found or inferred in a subject's benchmark statement.

So far, 22 benchmark statements have been published, but as the QAA guidelines note, 'many (but not all) of these statements embody within them the skills and behaviours that underpin personal development planning' (QAA, para. 14). A notable example that does include such behaviour is the General Business and Management benchmark statement, which is included in the QAA guidelines:

- learning to learn and developing an appetite for learning; reflective, adaptive and collaborative learning: effective self-management in terms of time, planning and behaviour, motivation, self-starting, individual initiative and enterprise.

In contrast, the Economics benchmark statement confines itself to identifying only the subjectspecific and cognitive skills of the discipline. A review of the benchmark statement is planned to occur from July 2003, but in the meantime individual institutions will have to make their own decisions about the personal targets that students of economics should set themselves.

Economics will probably also face practical problems in devising any particular PDP scheme. Certainly in the absence of any 'professional' status, economics departments will probably choose a scheme based on Personal Development Profiles, where the objective is to support the learner. However, given the peripatetic nature of a lot of our teaching, particularly at level/stage 1 , there could be problems of jurisdiction. This could be further compounded given the three objectives of PDP, i.e. who is responsible for who and what? These are not insurmountable problems, but economics tutors will probably feel they are caught in the middle.

\subsection{The challenge for the tutor of economics}

From the preceding sections, it is clear that the implications for tutors depend entirely on what scheme their particular institution will choose. However, tutors can expect to contribute to any scheme either as a mentor or in a planning capacity.

Peters (2002) reports that a key response of students to PDP centred on staff attitudes: "if the staff don't value the process then why should I?" (Peters, 2002, p.9). Factors that can leave tutors disinclined towards PDP include: the perception that more content time in lectures will have to be given over to supporting the process; the perception that the initiative is an external imposition; and, perhaps more importantly, the feeling among tutors that there is little point in supporting the PDP process if the students are not engaging in it. Thus, the greatest risk to the successful implementation of PDP is the excuses of staff and students alike not to engage with PDP feeding off each other, leaving PDP consigned to some "learning support ghetto" (Peters, 2002, p.4). Nevertheless, where tutors are positive and developmental in their use of PDP there was greater student engagement (Peters, 2002). 


\section{Conclusion: creating a framework for reflective learning}

In terms of learning, creating a reflective habit in our students is the challenge being presented to tutors by the PDP initiative. However, the minimum outcomes make no explicit reference to it. The inference is that a more strategic approach to career and personal development should have an 'overspill' effect on academic development. Yet the only opportunity to witness such development seems confined to a third-year dissertation/project.

This raises the question: is it too much and too late to use the dissertation/project as the only opportunity where students can be encouraged and supported to adopt a reflective approach to their learning? Do we as tutors leave it to chance or do we take this opportunity to restructure our teaching material and curriculum to exploit the benefits of reflection at an earlier stage of the degree? After all, if as tutors we are to benefit from any changes (i.e. personal capability is developed so that it becomes self-sustaining), an early 'investment' at level/stage 1 would make sense.

The literature on reflection suggests that to adapt our current level/stage 1 module, we have to tackle the following.

Find ways to link our material to the student's existing inventory of understanding - which as the degree progresses should include a greater body of economic understanding

Luckily, economics, more than most other disciplines, offers many opportunities to engage the student - after all, if the purpose of economics is to understand how people make choices, then economics is about the student as well. To improve the student's initial comprehension of economics, more could be done to associate our theories with their own experiences. Our task, compared to that confronting the politics tutor, is perhaps easier - for them there are certainly few opportunities to exploit the student's previous experiences when explaining the events leading up to the Russian revolution!

Provide a way that students can build an 'inventory' of skills, knowledge and understanding that they can refer to when evaluating their academic progress

This is perhaps less easy to achieve - in effect, tutors would be devising a module-specific progress file. However, exercises in reflection could be confined to core concepts. For microeconomic principles, these might include: price elasticity of demand, normal profit, profit maximisation, externalities and so on. For macroeconomic principles, these might include: the multiplier, speculative demand for money, the quantity theory of money and so on. Here, students could be encouraged to apply the verbs used in Bloom's (1956) taxonomy to ask themselves the following questions regarding the chosen concept or topic: 


\begin{tabular}{|c|c|c|}
\hline \multirow[t]{5}{*}{ Can I ... } & $\begin{array}{l}\text { define it? } \\
\text { reproduce it? }\end{array}$ & Knowledge \\
\hline & $\begin{array}{l}\text { give examples of it? } \\
\text { interpret it? } \\
\text { illustrate it? } \\
\text { estimate it? }\end{array}$ & Comprehension \\
\hline & $\begin{array}{l}\text { demonstrate it? } \\
\text { tabulate it? } \\
\text { manipulate it? } \\
\text { verify it? } \\
\text { apply it? }\end{array}$ & Application \\
\hline & $\begin{array}{l}\text { differentiate it? } \\
\text { account for ... using it? } \\
\text { confirm ... with it? } \\
\text { illustrate how ... with it? } \\
\text { infer from it? }\end{array}$ & Analysis \\
\hline & $\begin{array}{l}\text { imply ... with it? } \\
\text { propose ... using it? } \\
\text { conclude ... using it? }\end{array}$ & Synthesis \\
\hline
\end{tabular}

This checklist should help students to diagnose why they are having difficulty with a particular topic. A good 'warm-up' exercise - for example, for the first seminar contact - might be to ask students to use the Thesaurus feature in Microsoft Word to find alternative meanings for each of the verbs.

\section{Provide clearer academic targets for the students to aim at}

Depending on what 'audit' is undertaken during the planning phase of an overall PDP programme, this may occur anyway.

\section{Coach the student in reflective learning}

Presumably, initially this would simply involve explaining the role of reflection, not only in learning but in economic thinking as well. Beyond this, time would have to be found to allow students to experiment with the process. To this end the exercise detailed above (or a similar exercise) could form the basis of dedicated seminars timetabled to occur at regular intervals during the course. In terms of evaluating the student's progress, many of us might already be doing this by including peer assessment and self-assessment within the curriculum.

Clearly, to coach the students in reflection at level 1, time will have to be found not only to explain the nature of this process-orientated approach but also to allow the students to explore the processes, with the appropriate support. However, the loss of a couple of hours of content delivery may in the long run prove more cost effective as students progress to their final year. 


\section{Top Tips}

- Personal Development Planning should be viewed positively, since it can provide benefits to staff as well as students, giving structure and direction to elements of teaching that have often been haphazard.

- PDP is most effective when it is a mainstream academic activity, linked to the learning objectives/outcomes of programmes, undertaken regularly, and supported and valued by staff.

- Successful PDP is likely to involve each student having regular access to an appropriate named individual staff member who will support (and challenge) the student.

- PDP requires that universities create a structured process by which students can engage in reflection, recording and planning.

- PDP requires that learning outcomes of courses be explicit in terms of intended outcomes, processes and performance criteria.

- Students' career development is enhanced by reviews or audits of courses to identify explicitly the key skills that courses either use or develop.

- The encouragement and support of students in the adoption of a reflective approach to their learning should not be left to a third-year dissertation/project but developed from year 1 .

- Students will require some coaching in reflective learning to explain the role of reflection in economic thinking.

- Despite the various benefits to students, because PDP places additional demands on them it should come as no surprise if student conservatism is one of the principal sources of resistance to the development of PDP 


\section{References}

Bloom, B. S. (1956) Taxonomy of Educational Objectives, 1: Cognitive Domain, Longman, London.

Bolhuis, S. (In press 2002) 'Towards process-orientated teaching for self directed life-long learning: a multidimensional perspective', Learning and Instruction. Uncorrected proof available through http://www.sciencedirect.com/

Dewey, J. (1933) How We Think, D. C. Heath and Co., Boston, MA.

Fazey, D. M. A. and Fazey, J. A. (2001) 'The potential for autonomy in learning: perceptions of competence, motivation and locus of control in first-year undergraduate students', Studies in Higher Education, vol. 26, pp. 344-61.

Habermas, J. (1971) Knowledge and Human Interests, Heinemann, London.

HEQC (1997) Graduate Attributes Programme, Final Report

Heylings, D. J. A. and Tariq, V. N. (2001) 'Reflection and feedback on learning: a strategy for undergraduate research project work', Assessment and Evaluation in Higher Education, vol. 26, pp. 153-64.

Jackson, N. J. (2001) Building Capacity to Support PDP: An Optimistic Vision of Large Scale and Complex Change, LTSN Generic Centre and University of Surrey, http://www.ltsn.ac.uk/genericcentre/projects/PDP.

Kolb, D. (1994) Experiential Learning as the Science of Learning and Development, Prentice Hall, Englewood Cliffs, NJ.

Kreber, C. (1998) 'The relationships between self-directed learning, critical thinking and psychological type and some implications for teaching in higher education', Studies in Higher Education, vol. 23, pp. 71-86.

Main, A. (1985) 'Reflection and the development of learning skills', in D. Boud, R. Keog and D. Walker (eds), Reflection: Turning Experience into Learning, Kogan Page, London.

Moon, J. (2002) Reflection in Higher Education Learning, PDP Working Paper 4, LTSN Generic Centre, http://www.ltsn.ac.uk/genericcentre/network/PDP.

Peters, J. (2002) The Student Qualities Profile Experience at University College Worcester: Introducing PDP in HE.

Rowson, M. (2000) 'Learning to learn: more than a skill set', Studies in Higher Education, vol. 25 , pp. 225-38.

Schon, D. (1983) The Reflective Practitioner, Jossey-Bass, San Francisco.

Schon, D. (1987) Educating Reflective Practitioners, Jossey-Bass, San Francisco.

Sumison, J. and Fleet, A. (1996) 'Reflection: can we assess it? Should we assess it?', Assessment and Evaluation in Higher Education, vol. 21, pp. 121-30.

Swann, J. (1998) 'How can we make better plans?', Higher Education Review, vol. 31, pp. $37-55$. 
Vermetten, Y. J., Vermunt, J. D. and Lodewijks, H. G. (2002) 'Powerful learning environments? How university students differ in their response to instructional measures', Learning and Instruction, vol.12, pp. 263-84.

Waeytens, K., Lens, W. and Vandenberghe, R. (2002) “Learning to learn”: teachers' conceptions of their supporting role', Learning and Instruction, vol.12, pp. 305-22.

\section{Websites}

QAA benchmark statements: www.qaa.ac.uk/crntwork/benchmark/benchmarking.htm

QAA Guidelines on HE Progress Files: www.qaa.ac.uk/crntwork/progfilehe/contents.htm

LTSN Generic Centre (numerous examples of how PDP is being implemented in higher education including NUS initiatives): www.ltsn.ac/genericcentre/projects/pdp/examples/

Centre for Recording Achievement (CRA): www.recordingachievement.org

Personal Development Planning in Higher Education (Scotland) Network: www.eds.napier.ac.uk/PDP

PADSHE: Personal and Academic Development for Students in Higher Education, Nottingham University, including its electronic partner Personal Academic Records (PARS): www.nottingham.ac.uk/padshe

Integrated Personal and Academic Development Programmes within the Curriculum at the University of Manchester: www.ma.ac.uk/ra/indextra.

Liverpool Universal Student Interactive Databases (LUSID), a web based personal development planner: http://lusid.liv.ac.uk

Developing a Progress File for Higher Education at the University of Leeds: www.leeds.ac.uk/PDP

Progress Files in an Integrated Tool for Student Management of Study Programmes, led by Oxford Brookes and Thames Valley Universities:

Email Khcooper@brookes.ac.uk

Student Qualities Profile at UWC and supporting National Teaching Fellowship work: www.worc.ac.uk/LTMain/LTC/Profile/menu.html 